\title{
Microplastics in the atmosphere: a review
}

\author{
Nazima Habibi ${ }^{1}$, Saif Uddin ${ }^{1}$, Scott W. Fowler ${ }^{2,3}$, Montaha Behbehani ${ }^{1}$ \\ ${ }^{1}$ Environment and Life Sciences Research Center, Kuwait Institute for Scientific Research, Safat 13109, Kuwait. \\ ${ }^{2}$ School of Marine and Atmospheric Sciences, Stony Brook University, Stony Brook, NY 11794-5000, USA. \\ ${ }^{3}$ Present address: Institute Bobby, 8 Allée des Orangers, Cap d'Ail 06320, France.
}

Correspondence to: Dr. Saif Uddin, Environment and Life Sciences Research Center, Kuwait Institute for Scientific Research, Jamal Abdul Nasser Street, Safat 13109, Kuwait. E-mail: sdin@kisr.edu.kw How to cite this article: Habibi N, Uddin S, Fowler SW, Behbehani M. Microplastics in the atmosphere: a review. J Environ Expo
Assess 2022;1:6. https://dx.doi.org/10.20517/jeea.2021.07

Received: 18 Nov 2021 First Decision: 27 Dec 2021 Revised: 3 Jan 2022 Accepted: 17 Jan 2022 Available online: 25 Jan 2022

Academic Editor: Stuart Harrad Copy Editor: Yue-Yue Zhang Production Editor: Yue-Yue Zhang

\begin{abstract}
Microplastics (MPs) are ubiquitous environmental contaminants of considerable persistence and have been a global concern for the past decade. Recently, atmospheric MPs have gained attention. The presence of MPs in the air has been reported from different regions and in air masses over water bodies, demonstrating MPs' capability of long-range transport and wide spatial distribution away from their source of origin. This review of atmospheric MPs raises questions about the validity and legitimacy of approaches adopted for assessing MP in indoor and outdoor aerosols. The review also provides insight into active and passive sampling techniques and draws attention to the use of the data produced. MP abundance in the atmosphere varies widely among studies due to the disparities in methods employed and the heterogeneity in reporting, making comparisons across spatio-temporal domains infructuous. This review also highlights the paucity of data on atmospheric MPs, and the eminent need to harmonize the methodology for generating a useful comparable dataset that can be used for human health risk assessments.
\end{abstract}

Keywords: Airborne microplastic, active sampling, passive sampling, indoor, outdoor aerosol, atmospheric fallout, dust

\section{INTRODUCTION}

Plastic waste has become a menace on a global scale. The environmental concern emanating from this waste 
stream has generated a great deal of scientific interest. With 8.3 billion metric tons of plastics produced between 1950 and 2015, 75.9\% was dumped as waste ${ }^{[1]}$. By 2050, it is predicted that about 12,000 million metric tons of plastic debris will be present in landfills ${ }^{[2]}$. Approximately 8.75 million metric tons of plastic enter our ocean each year from land-based sources ${ }^{[3]}$ and comprise $61 \%-87 \%$ of marine litter ${ }^{[4,5]}$. The problem is further exacerbated when plastic breaks down into smaller microplastics (MPs) ( $1 \mu \mathrm{m}$ to $5 \mathrm{~mm}$ ) and nanoplastics $(<1 \mu \mathrm{m})$ due to biotic and abiotic degradation ${ }^{[0,7]}$. Reports suggest that $>5.25$ trillion plastic particles sized between 0.33 and $4.75 \mathrm{~mm}$ are currently floating in the world's oceans ${ }^{[8]}$. A more recent assessment by Uddin et al. ${ }^{[9]}$ indicates that globally treated effluent from wastewater treatment plants contributes $1.47 \times 10^{15} \mathrm{MPs}$ per annum, while discharge of untreated wastewater disposal adds another 3.85 $\times 10^{16} \mathrm{MPs}$ annually to the aquatic environments. Microplastics are found in all environmental matrices of the aquatic and terrestrial environments. The observations are well documented in 6551 published articles up to 3 May 2021.

A few studies, just over four dozen thus far, have looked at MPs in atmospheric aerosols. Aerosols are being identified as a significant pathway for inhalation of MPs by humans ${ }^{[10-14]}$. A recent study suggested that MPs can be transferred up to a distance of some $95 \mathrm{~km}^{[15]}$. There are 48 studies (as of November 2021) reporting MPs in dust, aerosols, wet and dry atmospheric deposition, snow, etc..$^{[1,15-26]}$. MPs in the air are released from wear and tear of clothing material ${ }^{[27-29]}$, by washing and drying ${ }^{[30]}$, erosion of synthetic rubber tires, deterioration of house furniture, emissions from the synthetic textile industry, emissions from vinyl chloride and polyvinyl chloride (PVC) industries, and contamination from city dust ${ }^{[18-21]}$ [Figure 1]. In addition, substantial quantities of plastics are being burned in open landfills on a daily basis, which results in the volatilization of various harmful compounds that inevitably integrate into the atmospheric $\operatorname{aerosol}^{[31,32]}$.

Considering the finite information available on this vital issue of MPs in aerosol, it has only limited usefulness. Although these studies suggest the omnipresence of MPs in aerosol, they have often used noncomparable techniques for the sample collection, processing, and identification of microplastics in indoor or outdoor aerosol, dust, and snow. The need to standardize these methodologies for making data comparable across spatio-temporal domains seems eminent for improved understanding of the human health implications in relation to inhalation exposure to $\mathrm{MPs}^{[26]}$. This review intends to highlight these issues. It also discusses the lack of information on the inhalable and respirable fraction of MPs in most reported literature.

\section{HEALTH IMPLICATIONS OF MICROPLASTICS}

Studies have reported localized inflammation and genotoxicity among humans due to inhalation of $\mathrm{MPs}^{[1,24,33]}$. Contrary to popular wisdom, where we expect smaller MPs to affect the human pulmonary system, in one study, fibers up to $250 \mu \mathrm{m}$ were detected in the human lung ${ }^{[34]}$. Other studies reported fibrous MPs could avert clearance mechanisms and persist in the lungs ${ }^{[34,35]}$. Some others have observed reduced lung capacity, coughing, and breathlessness ${ }^{[36-38]}$. Pauly et al ${ }^{[34]}$ found fibers in 99 of 114 malignant lung specimens. On the other hand, a recent study indicated that MP deposition is more likely to occur in the upper airway tract (i.e., nose, mouth, and throat) when inhaled and would reach the gut if ingested ${ }^{[7,25]}$. Fine MPs are believed to translocate to the circulatory system and other organs ${ }^{[3,39]}$.

Studies looking at MP inhalation by humans are $\operatorname{rar}^{[12,34]}$, and equally scarce are the inventories to make reliable human health risk assessments. A study conducted in Australia revealed mean MP inhalation rate $\left(0.2 \pm 0.07 \mathrm{mg} / \mathrm{kg}-\mathrm{B}_{\mathrm{w}} /\right.$ year and $12,891 \pm 4472$ fibers/year) to be highest $\left(0.31 \mathrm{mg} / \mathrm{kg}-\mathrm{B}_{\mathrm{w}} /\right.$ year $)$ for the below 0.5 year age group ${ }^{[24]}$. 


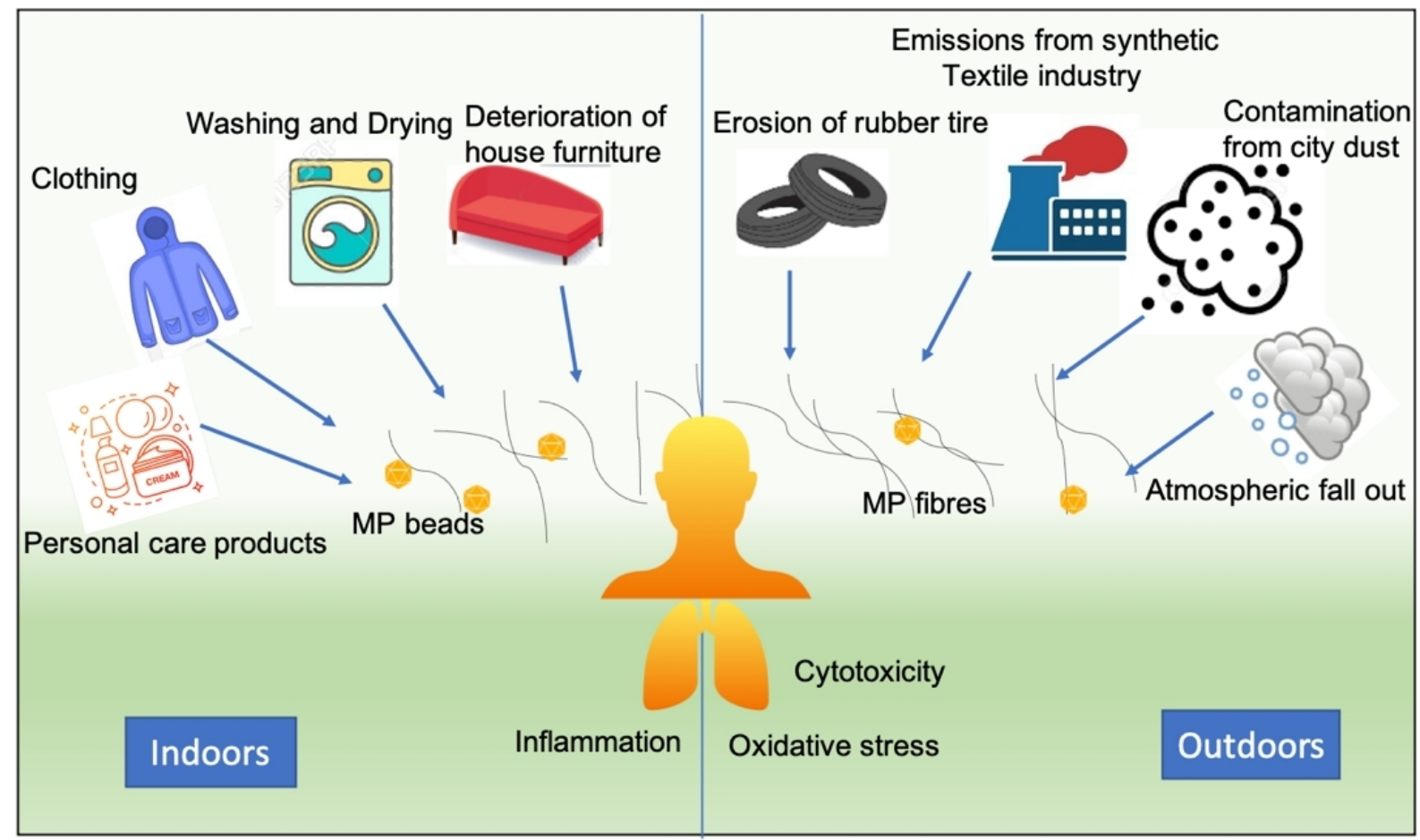

Figure 1. Sources of microplastics in the atmosphere and their health implications.

The primary questions are as follows: what are the reasons for the pulmonary diseases from MP inhalation? Is it the presence of MPs (polymers themselves) or the many additives, dyes, and pigments which are part of plastic production? Conversely, is it several factors together? Could these pulmonary diseases be more than inflammation, which is documented ${ }^{[13,23]}$ ? More than 4000 compounds are used in plastic manufacturing, many of which are not firmly bound to the polymer and make them susceptible to being released into the surrounding environment ${ }^{[13]}$. Could these additives lead to other health effects such as reproductive toxicity, carcinogenicity, and mutagenicity ${ }^{[13,24,40,41]}$ ? Therefore, the ability for sorption and toxicity of MP in other environmental matrices has attracted the attention of researchers across the world ${ }^{[4,10,19,42-59]}$. Airborne MPs may act as a vector for transport of the particle reactive pollutants, including polycyclic aromatic hydrocarbons, metals released from traffic emissions, and microorganisms to human lungs ${ }^{[11]}$. The inhalation of these MPs thereby poses a potential threat to human health ${ }^{[60]}$ and may cause chronic symptoms ${ }^{[6]}$. A suite of contaminants such as plasticizers, flame retardants, antimicrobial agents, and Bisphenol A (BPA) can be released during MP degradation ${ }^{[2,63]}$. A recent study presented the occurrence of BPA in the urban atmosphere of the city of Córdoba, Argentina ${ }^{[64]}$, with a concentration gradient of: industrial area $>$ urban area $>$ university campus. The results of this study are comparable to those reported in other cities of the world ${ }^{[6]}$. Other contaminants such as phthalates are also present in aerosol ${ }^{[66]}$. However, the magnitude of harm these MPs may cause to human health has not yet been well established ${ }^{[17,41,66]}$. Correlation can be drawn with other published studies where the fibers deposited in terminal bronchioles, alveolar ducts, and alveoli resulted in chronic inflammation, granulomas, or fibrosis ${ }^{[4]}$. In another study, fibers of asbestos, silica, and diesel exhaust were related to secondary genotoxicity due to continuous formation of reactive oxygen species ${ }^{[67]}$. Increased incidence of interstitial lung disease was associated with inhalation of MPs; however, these are based on assays where nonenvironmental concentrations were used ${ }^{[16]}$, raising concerns of whether we are establishing realistic correlations. 


\section{Sample collection}

Studies on atmospheric MPs have used different techniques for sample collection, i.e., active and passive sample collection techniques. The sampling techniques used for MP collection in indoor and outdoor aerosols are summarized in Supplementary Table 1. Out of the 38 outdoor studies, 21 have used passive sampling and 17 have collected samples using an active sampler. In indoor studies, active samplers were used in six studies and passive in five.

\section{Active sampling}

The active collectors operate on drawing the aerosol sample using some device, commonly a vacuum pump. These pumps operate with different capacities, some drawing hundreds of liters of air per minute (usually regarded as high volume air samplers), others drawing a couple of liters per minute (low volume air samplers $)^{[14,68]}$. The advantages of the active sampling technique are a known volume of aerosol is drawn, and, usually, a large volume of sample can be collected relatively quickly. It will produce comparable data across the spatio-temporal domain. The technique also enables to work out concentrations per unit volume. Active sampling is a well-established and accepted technique that has been adopted for years to monitor atmospheric pollutants, particularly microbes, carbon, lead, and mercury ${ }^{[6,70]}$. The active samplers require a power source, some basic skills to operate them, and are more expensive to procure and operate compared to passive samplers. Most of the active samplers deployed use a media/collection substrate; few authors have mentioned use of quartz, glass-fiber, or cellulose filter. The question remains on retrieval of an MP sample, as procedural blanks are not always done. Our experience shows significant cross-contamination and loss of sample by using a filter. In our experiments, we tried using a six-stage aluminum impactor for collecting size-fractionated aerosol sample, which gives the most realistic results we have obtained thus far.

\section{Passive sampling}

Passive sampling usually provides a time-integrated sample collected via dry and wet atmospheric deposition at a specific location such as deposition over a surface (MP settling). These samplers come in various forms such as simple funnels, rain gauges, bottles, and planar surfaces that allow atmospheric deposition [Figure 2]. While these samplers cannot be used to assess the concentrations per unit volume of aerosol, they can give an idea of MPs per unit area. Passive samplers are cheaper and easier to deploy but are highly influenced by local weather phenomena, elevation, and angle of deployment. Besides, they cannot be used for a very short period of deployment from minutes to a few hours. Hence, the choice of sampler depends on the scientific objective(s), whether one is interested in long-term mass accumulation rates of MPs or MP concentration in aerosol for health risk assessments.

\section{Sample type}

Outdoor air

Out of the 48 studies on MPs in atmospheric aerosol, 37 targeted the outdoor aerosol [Figure 3]. Twentyone used various passive sampling devices that included funnel with a collector bottle, rain gauge for aerosol collection, broom and spoon for collecting dust samples, and glass jar for collecting snow ${ }^{[1,18,19,71-75]}$. Four outdoor studies collected dust samples from street and apartment buildings using a broom and pan $^{[16,76-78]}$. Such samples are usually not pure aerosol samples. Seventeen studies used active samplers where a known quantity of air was passed through the filters or capturing devices ${ }^{[1,20,22,79-82]}$. Most of these samplers were low volume samplers drawing between $2.07 \times 10^{2} \mathrm{~mL} \mathrm{~min}^{-1}$ and $3 \times 10^{5} \mathrm{~mL} \mathrm{~min}^{-1}$ air.

\section{Indoor air}

There have only been 11 studies on MP in indoor air up until October 2021. A summary is included in Figure 3 [Supplementary Table 1]. Six studies sampled indoor air using active samplers ${ }^{[12,20,22]}$, and four collected indoor dust from non-carpeted apartment floors ${ }^{[78,83]}$, while another study collected atmospheric 


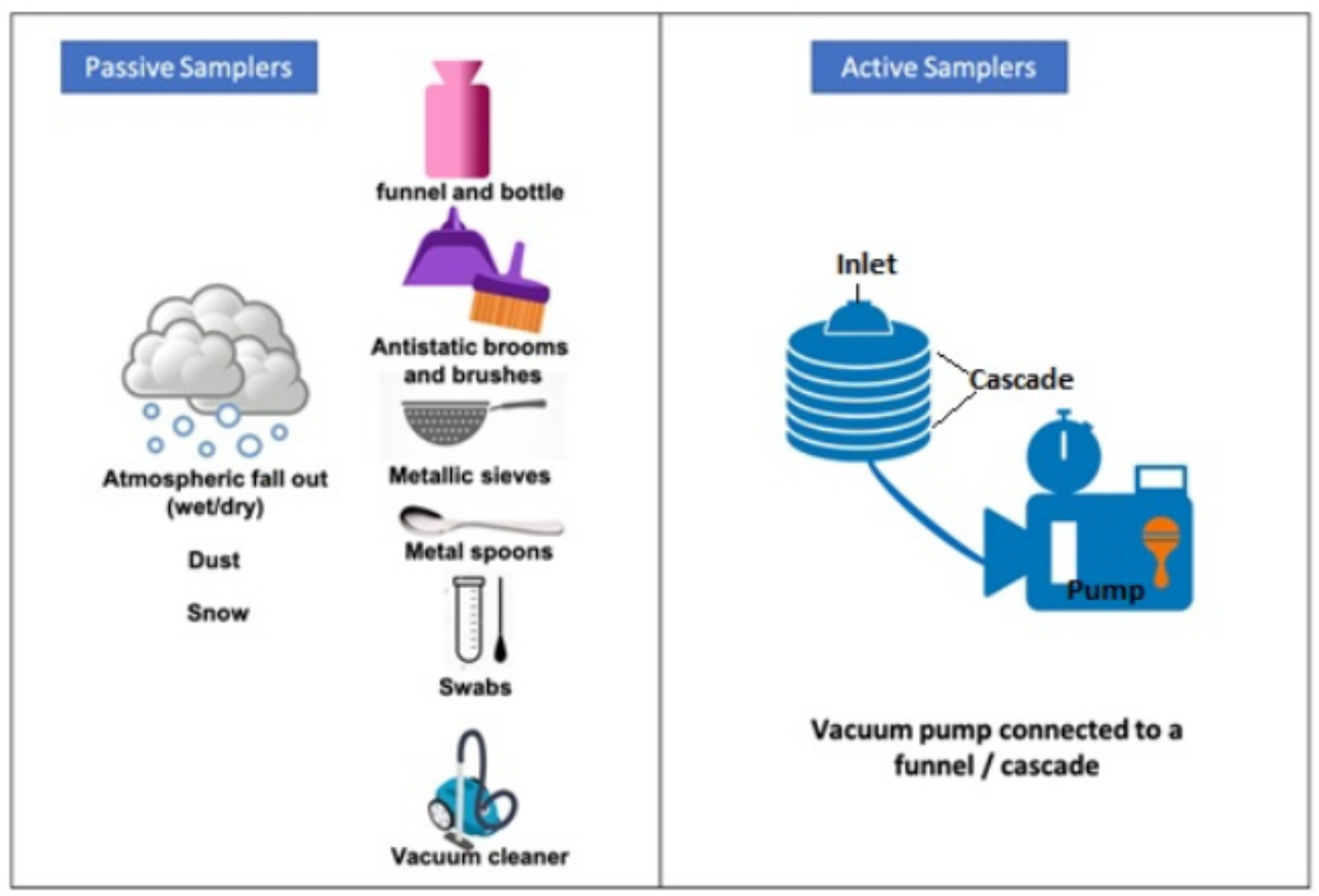

Figure 2. Modes and means of active and passive sample collection.

fallout passively at head height from households in the $\mathrm{UK}^{[84]}$. Different types of active samplers have been used for collecting indoor air samples. Dris et al. ${ }^{[20]}$ used a sampler that drew aerosol @ $8 \mathrm{~L} \mathrm{~min}^{-1}$ from two apartments and an office sampling a total volume of 2 and $5 \mathrm{~m}^{3}$. In a Danish study, an extremely complicated active sampling was used that involved a manikin simulating the human lungs ${ }^{[12]}$. Although this was an excellent approach, it is still not a standard method employed by people undertaking indoor air quality assessments, and thus cannot be compared to other assessments.

\section{Sample preparation}

Sample preparation is a critical step for segregating MP from environmental matrices. It becomes more important when a filter/substrate is used for aerosol collection. In a recent procedure developed by our group, we started collection of size-fractionated aerosol samples using an aluminum six-stage cascade impactor, without any substrate. We found that this process minimizes the processing step to microscopic examination of fibers and removal using a static charge. The aerosol is a complex mixture of inorganic (mineral), organic matter (pollen, fungi, microbes, soot, etc.), and MPs. The removal of MPs from this complex mixture often entrails chemical processing that includes digestion of organic matter using potassium hydroxide $(\mathrm{KOH})$, sodium hydroxide $(\mathrm{NaOH})$, hydrogen peroxide $\left(\mathrm{H}_{2} \mathrm{O}_{2}\right)$, enzymatic methods, or sodium hypochlorite $(\mathrm{NaClO})^{[15,19,85-89]}$. Some researchers have done acid digestions using hydrochloric acid $(\mathrm{HCl})$, nitric acid $\left(\mathrm{HNO}_{3}\right)$, and sulfuric acid $\left(\mathrm{H}_{2} \mathrm{SO}_{4}\right)$. Different studies have used various processing steps, namely filtration of sample on a glass or quartz fiber filters ${ }^{[18,19,24,73,78,81]}$ and digestion with $30 \%-35 \% \mathrm{H}_{2}$ $\mathrm{O}_{2}$ for days ${ }^{[15,16,22,23,75-77,79]}$. Some researchers have indicated that the use of $30 \% \mathrm{H}_{2} \mathrm{O}_{2}$ can lead to significant deterioration of MPs by decolorization, making them further difficult to distinguish from some natural fibers $^{[15,8,8,90,91]}$. A standardized protocol that can be effective for MP segregation is summarized in Figure 4. 


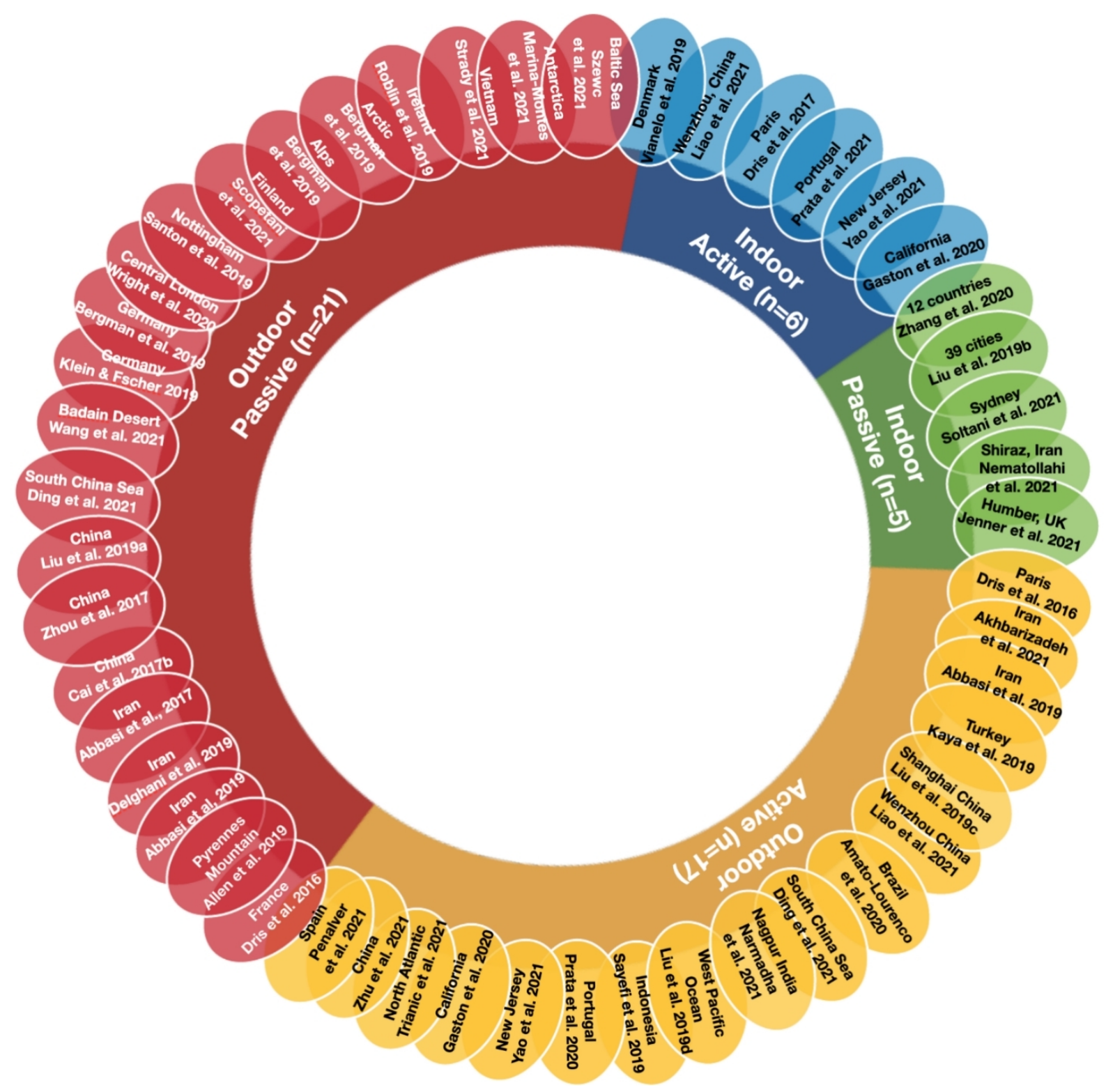

Figure 3. The numbers and types of samplings used in different indoor and outdoor studies.

This review of published studies highlights that authors have used different solutions such as $\mathrm{NaCl}$, sodium iodide $(\mathrm{NaI})$, and zinc chloride $\left(\mathrm{ZnCl}_{2}\right)$ for the density separation of MPs in the aerosol. Synthetic clothes, carpets, and upholstery are the most likely source of MPs in the air ${ }^{[29]}$; the likelihood of polyester/polyamide fiber domination in air samples is high. However, using $\mathrm{NaCl}$ for density separation will only float a fraction of the MP load in aerosols, while a fraction of polyamide (nylon) may remain non-buoyant. Figure 5 presents the polymer densities with respect to the commonly used solutions for density separation.

\section{Identification and characterization of microplastics in aerosol samples}

Identification of airborne MPs

Several methods of microplastic identification are reported. Some studies used a scanning electron microscope with an energy dispersive X-ray analyzer at a voltage of $3.0 \mathrm{kV}$ to identify the morphology of potential MPs. A very cost-effective test is the hot needle technique, in which particles can be tested to 


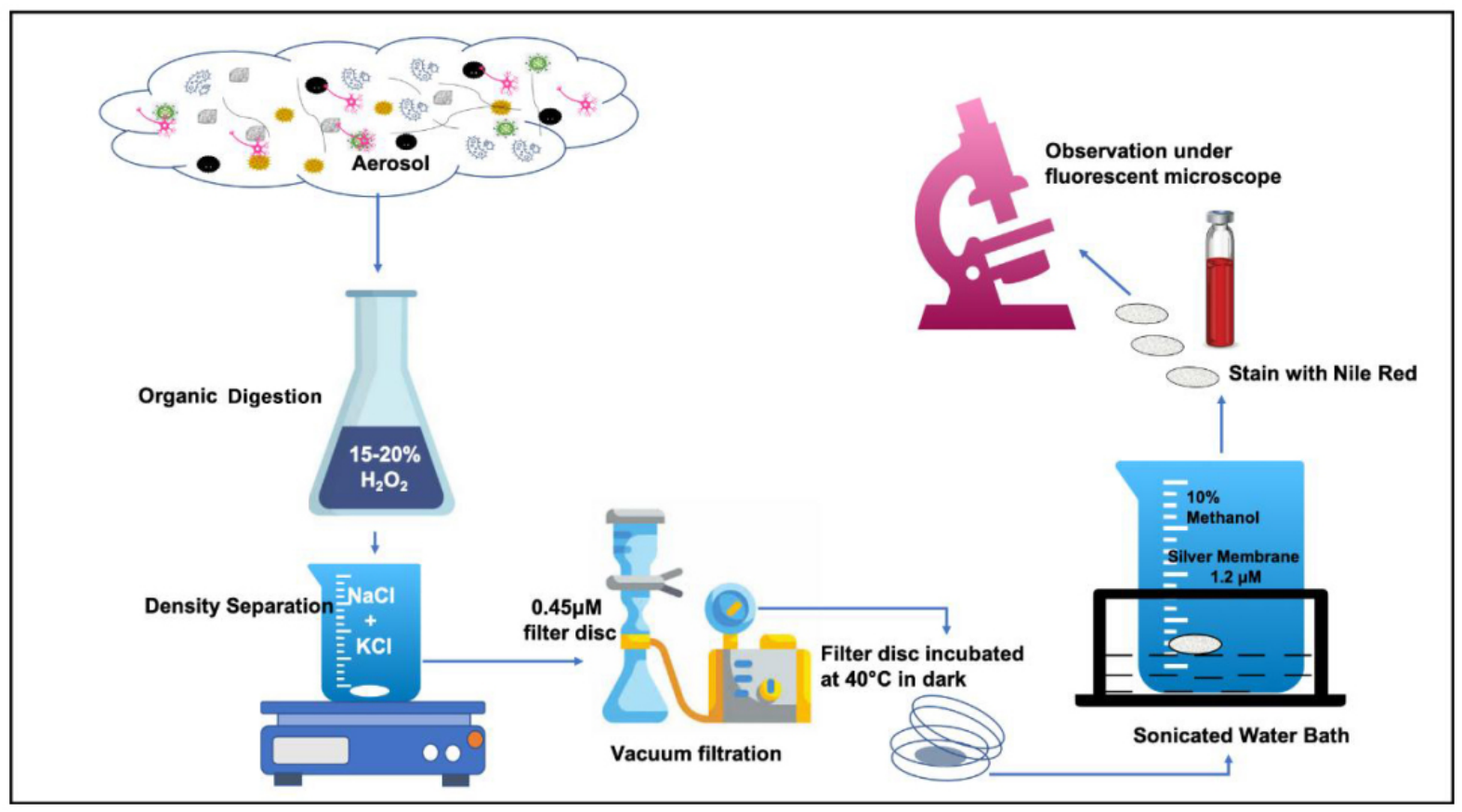

Figure 4. Pictorial representation of the steps involved in aerosol sample processing and microplastic identification.

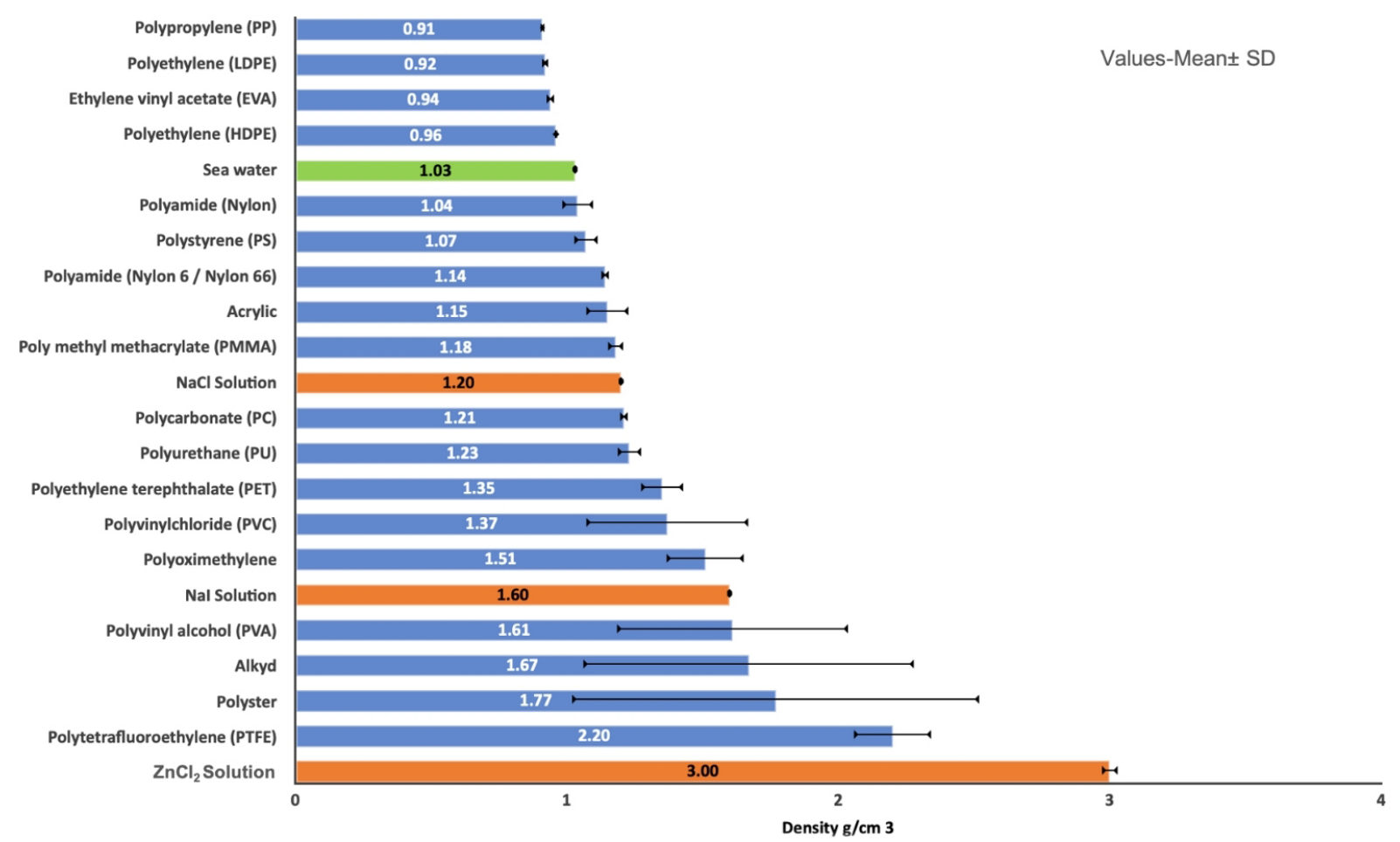

Figure 5. Polymer densities and corresponding solutions (modified after Uddin et al. ${ }^{[92]}$ ). Blue bars represent the polymer densities, orange bars are for the respective solutions used for density separation, and the green bar shows the density of seawater.

determine whether they are natural fibers or polymers ${ }^{[93]}$. The staining of segregated particles with Nile red and observation under a fluorescence microscope is another method. Several researchers have limited the 
observations to microscopic investigation without staining. However, generally, authors have used a twotier process for MP identification. An initial visual examination using a microscope where the large size MPs $(>500 \mu \mathrm{m})$ can be picked up based on the absence of cellular structure and thickness consistency along with their length, relatively homogenous coloring, and transparency is followed by a hot needle test and/or sometimes using staining using Nile red and observation under a fluorescence microscope. Sometimes these are followed by polymeric characterization through sophisticated spectroscopic methods such as microRaman spectroscopy ( $\mu$-RS), attenuated total reflectance Fourier transformed infrared (ATR-FTIR), or micro-Fourier transformed infrared spectroscopy ( $\mu$-FTIR).

\section{Characterization of airborne MPs}

Polymeric characterization of the MPs has been attempted by several researchers using techniques such as $\mu$ -FTIR, ATR-FTIR, $\mu$-RS, high-performance liquid chromatography-tandem mass spectrometry (HPLC-MSMS), and thermal desorption coupled with thermogravimetric analyses [Figure 6]. Three studies from $\operatorname{Iran}^{[16,76,7]]}$ only used microscopic examination to identify MPs, whereas, in a recent study, polymers were identified using $\mu$-RS $S^{[94]}$. Some other researchers in Hamburg, Germany ${ }^{[74]}$, Antarctica ${ }^{[95]}$, Ireland ${ }^{[96]}$, the North Atlantic Ocean ${ }^{[97]}$, New Jersey, USA ${ }^{[98]}$, and London, UK ${ }^{[99]}$ also used $\mu$-RS. A single study used HPLCMS-MS to identify MPs in 286 indoor house dust samples from 12 countries $^{[83]}$. All other studies reviewed used FTIR for polymeric identification. A single study used thermogravimetry-mass spectrometry to assess the levels of airborne polystyrene from an agricultural area in Spain ${ }^{[100]}$.

It is prudent to mention that these techniques have inherent differences. The ATR-FTIR and $\mu$-FTIR spectroscopy can be used for fibers up to 10 and $50 \mu \mathrm{m}$ particle size, respectively ${ }^{[12]}$. $\mu$-RS can be used to identify MPs up to $1 \mu \mathrm{m}$ in size ${ }^{[25]}$, giving it a technological superiority. However, FTIR has been favored in research due to its high throughput and comprehensive polymer spectral libraries.

Some researchers have been using polycarbonate, PTFE, and nylon filters, making the application of $\mu$-FTIR or $\mu$-RS a bit complicated as it interferes with the MP spectra. The preferred filter for $\mu$-FTIR and $\mu$-RS analysis is an anodisc (aluminum oxide) or a silver filter with a pore size of $0.2 \mu \mathrm{m}^{[15,101]}$. Py-GCMS, TD, and HPLC-MS-MS are other techniques that can be effectively used to identify MPs but cannot specify the count, shape, and size; instead, they give the concentration of a specific polymer in the sample.

Some points to ponder are: do we need polymeric identification for establishing the environmental concentration of MPs in aerosol? Will knowing the type of polymer make any difference to human risk assessment? Is the toxicity of each polymer different, and do we consider this when estimating the toxicity due to inhalation? If the answer to many of these questions is no, then is it not worth the time and resources that people spend on these studies.

\section{Types of airborne MPs}

Most of the studies published thus far, except for one study each from Iran, France, and Portugal, have done polymeric characterization. The most widely reported polymers in the aerosol are polyethylene (PE), polyethersulfone (PES), polyacetonitrile (PAN), polyamide (PA), polyethyleneterapthalate (PET), polystyrene (PS), polypropylene (PP), PVC, acrylic (AC), polycarbonate (PC), polyacrylic acid (PAA), ethylene-vinyl acetate (EVA), polytetrafluoroethylene (PTFE), ethylene propylene (EP), ethylene acrylic (EA), ethylene vinyl acetate (EVAC), polymethylacrylate (PMA), polyvinyl acetate (PVA), and polyurethane (PU) [Figure 7]. Their relative abundance is highly variable, in both type and quantity. The variation of sampling methods and identification techniques might have contributed to this variance. 


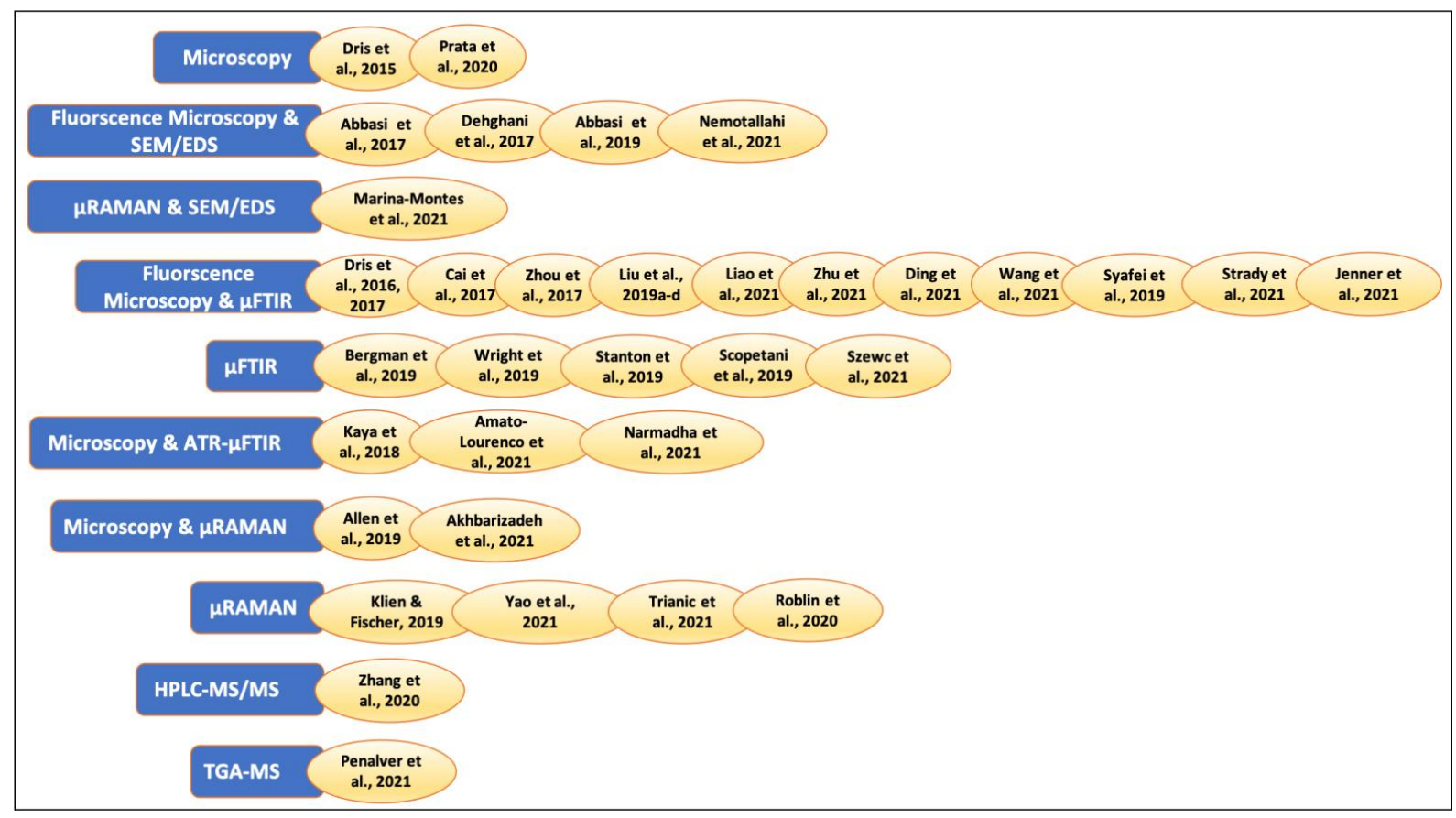

Figure 6. Techniques used for the identification and characterization of airborne MPs. The blue boxes represent the techniques, while their applications by different research groups are presented in the yellow circles.

\section{Microplastic inventories and physical properties}

Size of airborne MPs

The length of fibers in aerosol samples have been reported to range 50-600 $\mu \mathrm{m}$ with diameters ranging 7-15 $\mu \mathrm{m}^{[11]}$. Although there is a consensus on the upper and lower size limits of $\leq 5 \mathrm{~mm}$ and $1 \mu \mathrm{m}$, respectively ${ }^{[102-104]}$, for MPs, the smaller MPs are not well characterized. The smaller MPs have greater potential to be transferred via aerosolization ${ }^{[15]}$ to the human respiratory system. The sizes of MPs in the reviewed studies are highly variable; for example, the dominant size from Pyrenees Mountains was less than $300 \mu \mathrm{m}$, while the majority of fragments from Hamburg were $<63 \mu \mathrm{m}(\sim 60 \%)$, followed by $63-300 \mu \mathrm{m}$ $(\sim 30 \%)^{[74]}$. The dominant size of fibers in studies conducted in Paris was $200-600 \mu \mathrm{m}(\sim 40 \%)^{[18,19]}$. Most of the particles reported from China were $<500 \mu \mathrm{m}(\sim 50 \%)^{[105]}$. Snow samples were dominated by fine MPs of $<100 \mu \mathrm{m}(98 \%)$, of which $80 \%$ were $\leq 25 \mu \mathrm{m}^{[101]}$.

The size of fibers/particles/fragments in indoor samples is smaller compared to outdoor aerosol samples. The study conducted in Aviero, Portugal reported the median fiber size in indoor samples as $250 \mu \mathrm{m}$ compared to $299 \mu \mathrm{m}$ in outdoor samples ${ }^{[23]}$. Similarly, in California, the outdoor fibers $(104.8 \mu \mathrm{m})$ were double the size of indoor $(58.6 \mu \mathrm{m})$ ones $^{[106]}$.

\section{Reporting units of airborne MPs}

The inventories of atmospheric MPs are highly variable between studies, in terms of both occurrences and units of reporting [Supplementary Table 1]. For most of the studies where passive samplers were deployed, the results are reported in terms of MP $\mathrm{m}^{-2}$ day $^{-1}$, while others have given MPs per unit mass of dust sample $e^{[1,76-78,83]}$. The concentration of MPs in snow samples is reported as MPs per liter ${ }^{[101,107]}$. In contrast, the studies that have utilized active sampling have reported the MP concentration in per unit volume $\left(\mathrm{MP} \mathrm{m}^{-3}\right)$ except a single study that indicated MPs per day ${ }^{[108]}$. 


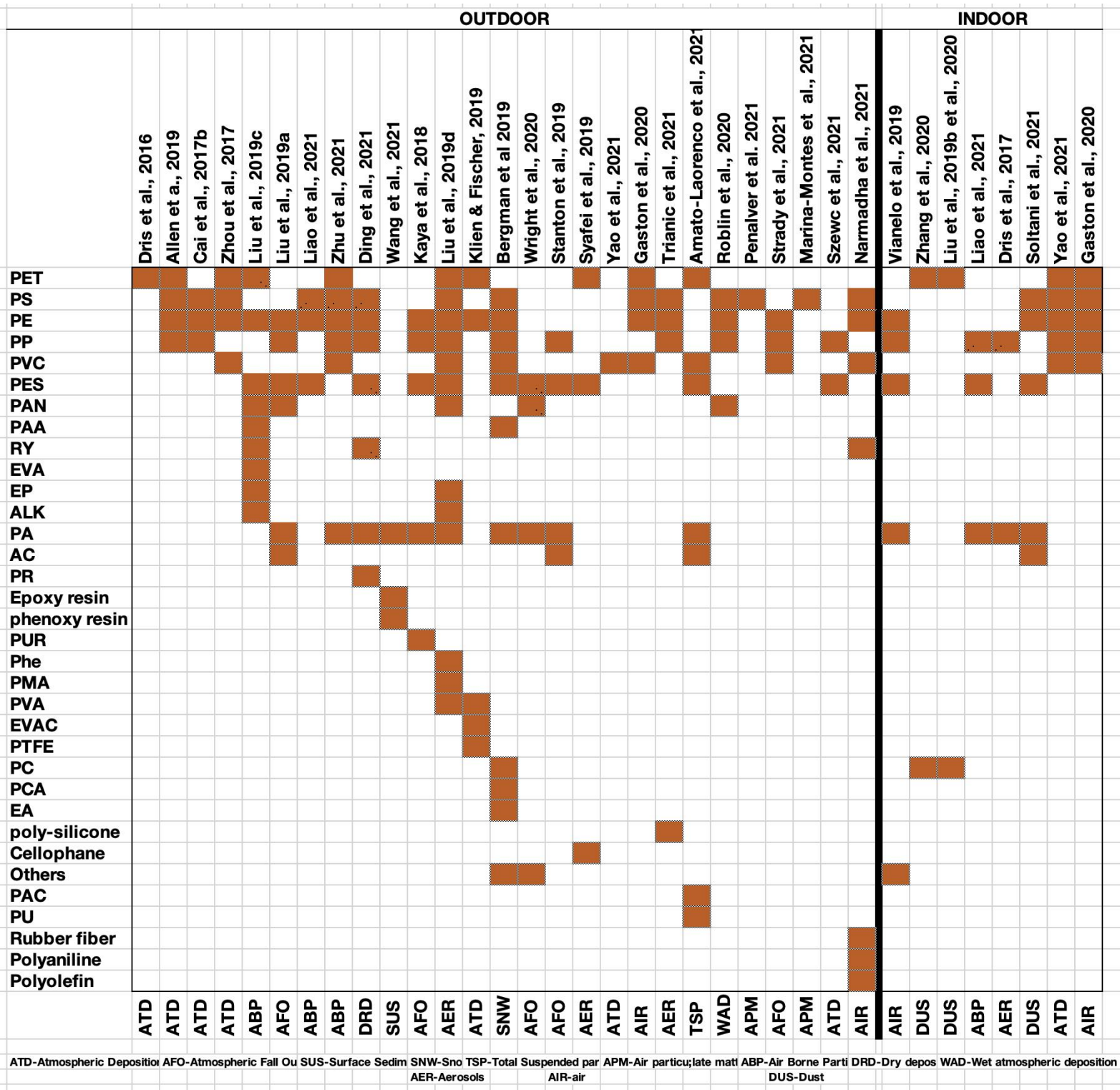

Figure 7. Types of polymers identified in the indoor and outdoor air samples. The types of polymers are listed on the left side of the yaxis. The top bar presents the studies conducted by corresponding research groups in indoor and outdoor aerosols. The types of samples are mentioned on the $x$-axis. The brown boxes indicate the presence of polymers in the respective sample.

The concentration of airborne MPs

There is a huge variation in the spatio-temporal concentration of MPs in aerosol [Figure 8]. The average MP concentration measured in outdoor samples in an urban and suburban area of Paris was between 53 and $110 \mathrm{MP} \mathrm{m}^{-2}$ day $^{-1[1,19]}$. In comparison, it was $275 \mathrm{MP} \mathrm{m}^{-2}$ day $^{-1}$ in Hamburg ${ }^{[74]}$, and the average MP concentration in the Pyrenees was $365 \mathrm{MP} \mathrm{m}^{-2}$ day $^{-1[15]}$. Microplastic concentrations determined using an active sampler in outdoor samples in Paris were between 0.3 and $1.5 \mathrm{MP} \mathrm{m}^{-3[20]}$. In megacities of China, fibers were the most dominant MPs and ranged between 175 and 602 particles $\mathrm{m}^{-2}$ day $^{-1[72,73]}$. In the eastern city of Wenzhou (China), MP concentration varied significantly between urban and rural sites, ranging from $51 \mathrm{MP} \mathrm{m}^{-3}$ in the mountains to $8865 \mathrm{MP} \mathrm{m}^{-3}$ in the city's apartments ${ }^{[22]}$. In Shanghai, the concentrations were between 0 and $4.18 \mathrm{MP} \mathrm{m}^{-3[80]}$. In Indonesia, the West Pacific Ocean, Denmark, Ireland, 


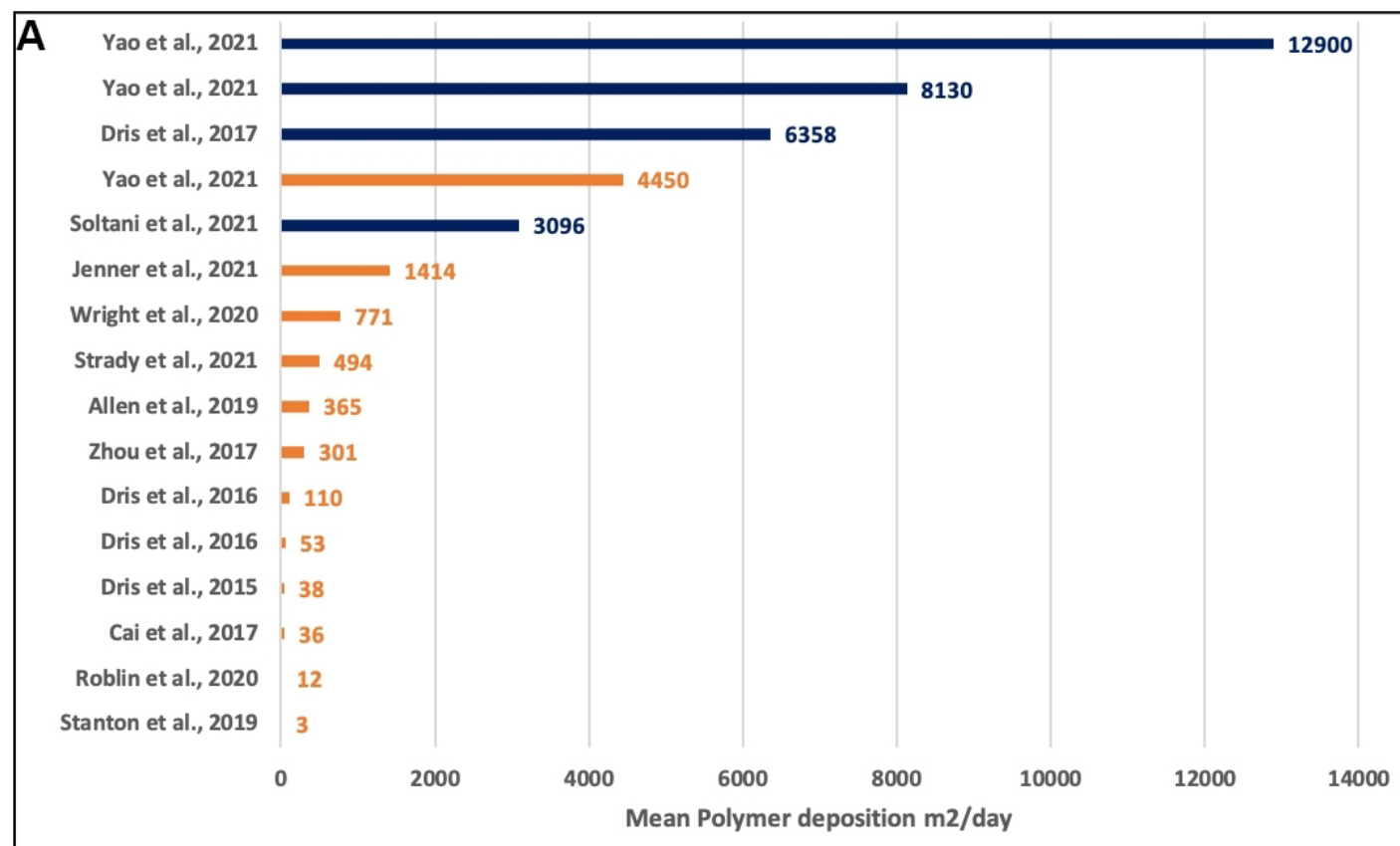

B

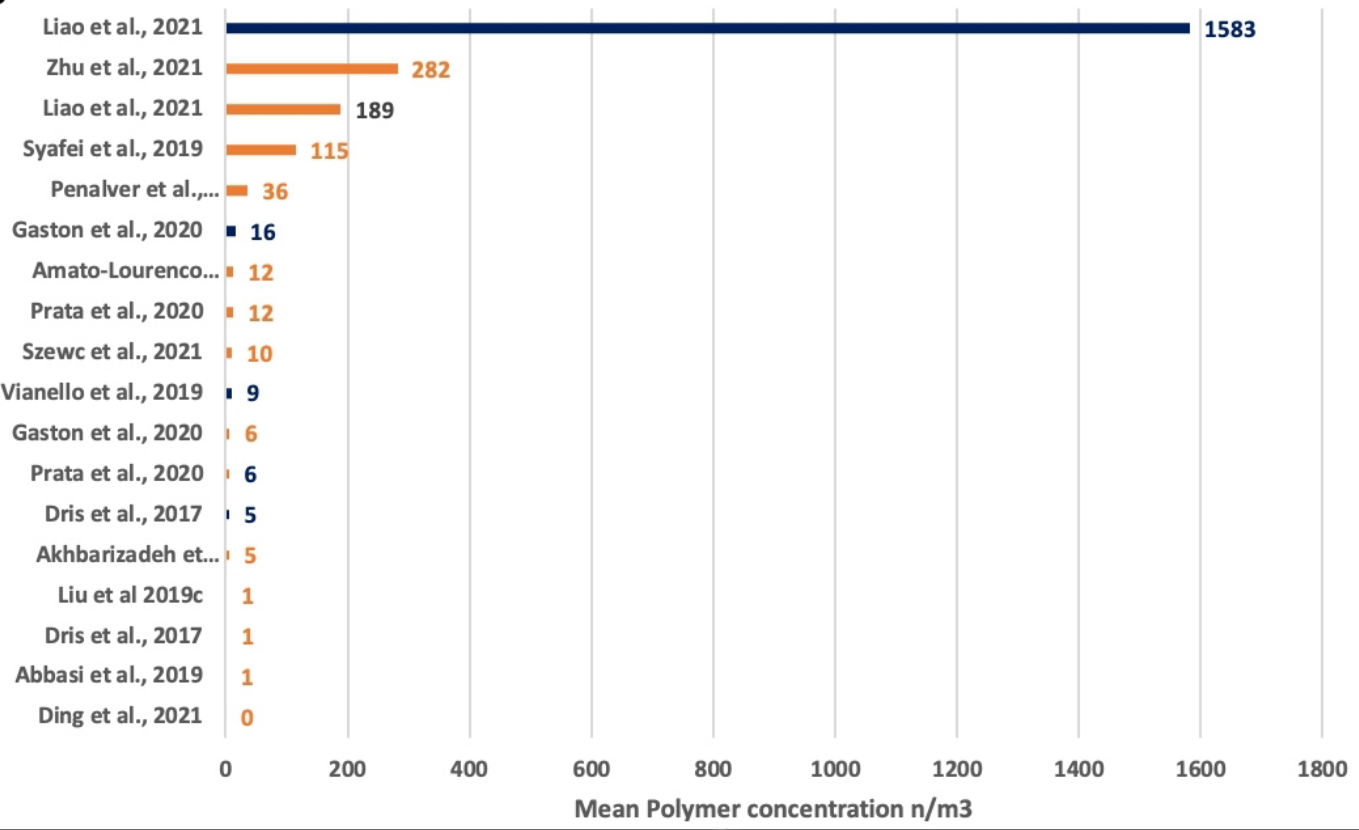

Figure 8. MP polymer (A) deposition rate and (B) concentration. The $y$-axis represents the research groups. Blue bar represents the indoor samples, whereas the orange bar shows the outdoor samples. The MP concentration/deposition values are written next to the bars.

Brazil, and California the concentrations were 132.75-174.97, 0-1.37, 1.67-16.2, 0-12, 0-24, and 0.6-5.6 MP $\mathrm{m}^{-3}$, respectively ${ }^{[1,66,81,82,96]}$. In the UK, the concentrations in Nottingham and Central London were 2.9 and $712 \pm 162$ particle $\mathrm{m}^{-2} \mathrm{day}^{-1}$, respectively ${ }^{[71,75]}$. In the indoor setting of the Humber region, $\mathrm{UK}$, the concentrations were $1414 \mathrm{MP} \mathrm{m}^{-2}$ day $^{-1[84]}$. In Vietnam, the dry and wet atmospheric deposition ranged between 71 and $917 \mathrm{MPs} \mathrm{m}^{-2} \mathrm{day}^{-1[109]}$. The concentration reported for the Alps and Arctic varied between a 
large range of 0.02 and $154 \times 10^{3} \mathrm{MP} \mathrm{L}^{-1[101]}$, while the average concentration in Finland was $117.1 \pm 18.4 \mathrm{MP}$ $\mathrm{L}^{-1[107]}$. This concentration of MP in the snow is several orders of magnitude higher than wet deposition and aerosols, even when reported from urban centers. In Sydney, the MP concentrations were $12 \mathrm{MP} \mathrm{m}^{-3[24]}$. In Gdynia, Poland on the Baltic Sea, the inventory of atmospheric MPs varied from 0 to $30 \mathrm{MP} \mathrm{m}^{-2}$ day $^{-1[110]}$. In Badain desert, China MP concentrations were $0.7 \pm 1.5$ to $11.7 \pm 15.5 \mathrm{MP} \mathrm{kg}^{-1[111]}$ (dust), and in the South China Sea were 0.013-0.063 MP m $\mathrm{m}^{-3[112]}$.

A study investigating indoor and outdoor fibers in air reported a higher indoor concentration ranging from 1 to $60 \mathrm{MP} \mathrm{m}^{-3}$ as opposed to a significantly lower outdoor concentration ranging between 0.3 and $1.5 \mathrm{MP}$ $\mathrm{m}^{-3[20]}$. Similar observations of higher MP in the indoor air $\left(1583 \pm 1180 \mathrm{MP} \mathrm{m}^{-3}\right)$ compared to outdoor air $\left(189 \pm 85 \mathrm{MP} \mathrm{m}^{-3}\right)$ were reported by Liao et al. ${ }^{[22]}$. The observations of Gaston et al. ${ }^{[106]}$ were similar as well; indoor concentrations were $3.3 \pm 2.9$ fibers $\mathrm{m}^{-3}$ and $12.6 \pm 8.0$ fragments $\mathrm{m}^{-3}$ compared to $0.6 \pm 0.6$ fibers $\mathrm{m}^{-3}$ and 5.6 \pm 3.2 fragments $\mathrm{m}^{-3}$ in outdoor air. The deposition rate of MPs in the ambient air on a roof of a building was only about $2 \%-8 \%$ of the indoor deposition rates ${ }^{[98]}$. In contrast, MP concentrations in outdoor $\left(12 \mathrm{MP} \mathrm{m}^{-3}\right)$ air were higher than those in indoor $\left(5 \mathrm{~m}^{-3}\right)$ air in Aveiro, Portugal ${ }^{[23]}$.

In summary, it is evident that average microplastic concentrations were higher in indoor environments than in outdoor aerosol, probably due to more sources, ventilation, and dilution ${ }^{[13,20,24]}$. It is prudent to mention that most people spend $70 \%-90 \%$ of their time indoors, which may enhance their exposure levels to MPs. Interestingly, microplastics generated indoors can frequently contaminate the environment outdoors, whereas only $30 \%$ of particulate matter produced outdoors can penetrate the indoor environment. This elucidates the importance of indoor environments as the main exposure source of airborne microplastics ${ }^{[113]}$.

\section{Shapes of airborne MPs}

Diverse shapes, including fiber, foam, fragment, and film, have been detected in the atmospheric MPs [Figure 9]. In Hamburg, more than $90 \%$ of MP detected were fragments and less than $10 \%$ were fibers ${ }^{[74]}$. Similarly, fragments $(89.6 \%)$ were dominant in Wenzhou, China, followed by fibers $(10.4 \%)^{[22]}$. A similar trend was observed in Badain Jaran Desert, China ${ }^{[111]}$, Busheher port of Iran ${ }^{[94]}$, and central London ${ }^{[26]}$. Approximately $87 \%$ of the MPs were fragments in the indoor air samples collected in Denmark ${ }^{[12]}$. On the other hand, MP research in other cities of China reported $67 \%-80 \%$ fibers, $<30 \%$ fragments, and $<3 \%$ granules. Films were reported in outdoor samples in Pyrenees Mountains ${ }^{[15]}$, Asaluyeh city, Iran ${ }^{[16]}$, Dongguan city, China ${ }^{[73]}$, Yantan city, China ${ }^{[72]}$, South China Sea ${ }^{[112]}$, central London, UK ${ }^{[71]}$, Surabaya, Indonesia ${ }^{[82]}$, New Jersey, USA ${ }^{[8 s]}$, and the Baltic $\mathrm{Sea}^{[110]}$. MP films were reported in the indoor samples from New Jersey, USA ${ }^{[98]}$ and Humber region, $\mathrm{UK}^{[84]}$. The single study in Asaluyeh city, Iran reported spherules (74\%) as the dominating type of MPs followed by films $(14 \%)^{[16]}$.

\section{Color of airborne MPs}

The microplastics consist of different colors with the most dominant ones being red, orange, yellow, white, grey, blue, green transparent, and black [Figure 10]. The use of color to identify potential sources of plastic debris is sometimes practiced ${ }^{[104]}$; however, this can be quite misleading. Several studies in this review have reported the color of the identified MPs [Supplementary Table 1]. Blue and red MPs were reported from Paris and China ${ }^{[18,73]}$, while black, blue, red, transparent, brown, green, yellow, and grey particles were reported from Shanghai, China ${ }^{[80]}$ and $\operatorname{Iran}^{[16,76,77]}$. Dark blue, white, transparent, and brown colored MPs were reported in aerosol samples from the West Pacific Ocean ${ }^{[81]}$. The colors were bright yellow to white in atmospheric deposition from Hamburg, Germany ${ }^{[74]}$. Black and grey MP fibers were found in passive fallout samples in Nottingham, $\mathrm{UK}^{[75]}$. The wet atmospheric deposits in Ireland were rich in red, blue, and yellow fibers ${ }^{[96]}$. White transparent fibers were detected in the ambient air samples collected from the streets of 


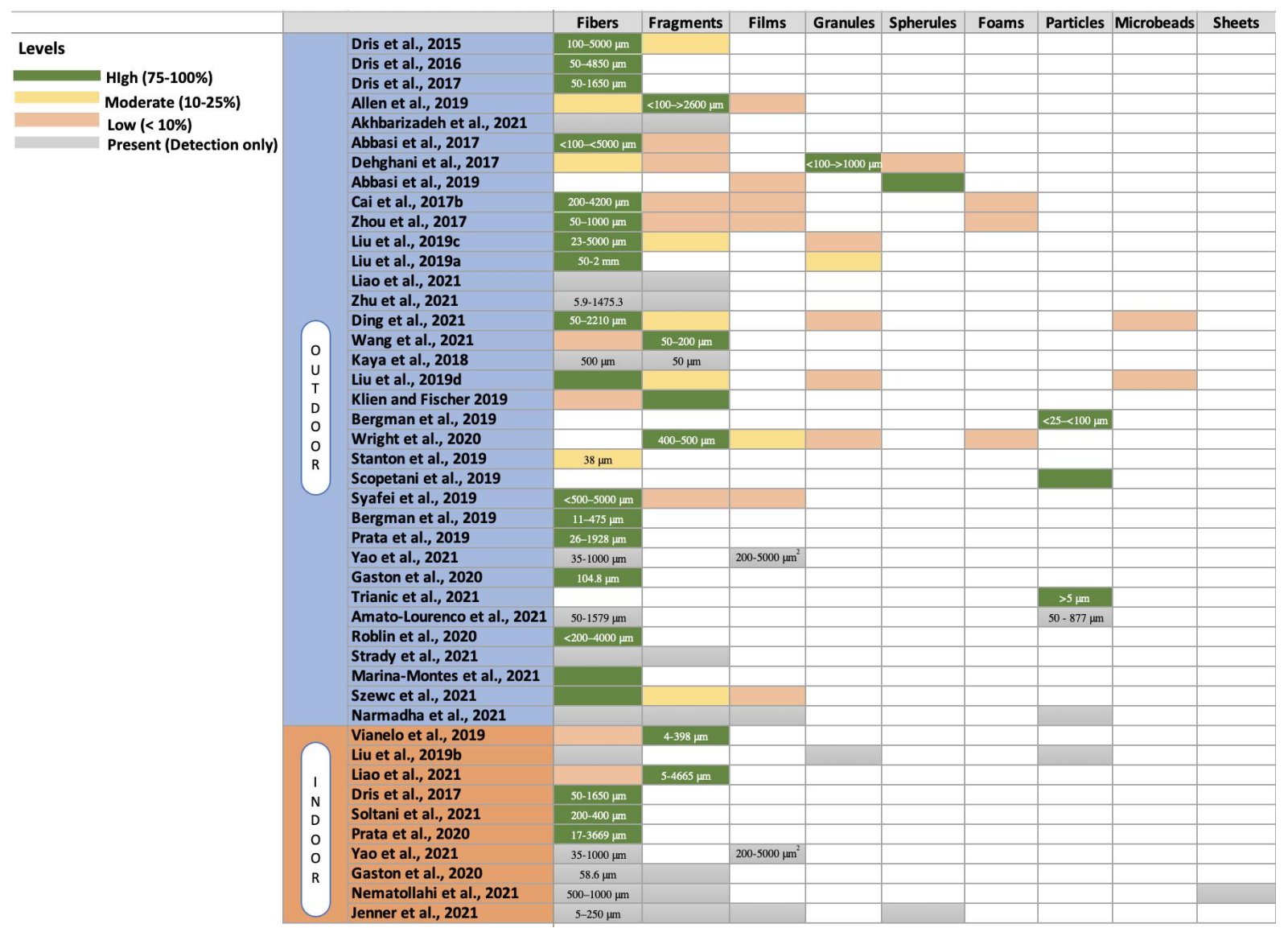

Figure 9. Shape and size of microplastics found in aerosols.

Nagpur, India ${ }^{[108]}$.

It is also prudent to mention that most of these studies have used $30 \%$ and $35 \% \mathrm{H}_{2} \mathrm{O}_{2}$ to digest the organic material, but this treatment can cause significant degradation of polymers in terms of both physical and chemical properties. One of the effects of such treatment can be the discoloration of microplastics. The other point that needs discussion is whether this information can be used in any way; e.g., can color be a reliable indication source?

\section{CONCLUSIONS}

The review highlights the limited information on MP in aerosol from only about four dozen studies. Even within these studies, different approaches have been used for sample collection, sample processing, and reporting units, making any direct comparisons across spatial and temporal domains incoherent. However, despite these limitations, it could be confidently inferred that MPs are more abundant in indoor compared to outdoor aerosol. The observation is not surprising as the sources of MPs are clothing, carpets, dryers, upholstery, etc., and there is less mixing dilution in the indoor environment compared to outdoors. Fibers and fragments are the predominant shapes of MPs in aerosol samples, with white, transparent, blue, red, and yellow being the most prevailing colors. The need of adapting standardized protocols for atmospheric MP research is evident from this review in order to make these assessments comparable, to establish spatiotemporal trends, and for undertaking comprehensive human health risk assessments. The choice of sampling is very important, and, based on the research question, it should be appropriately designed. Use of 


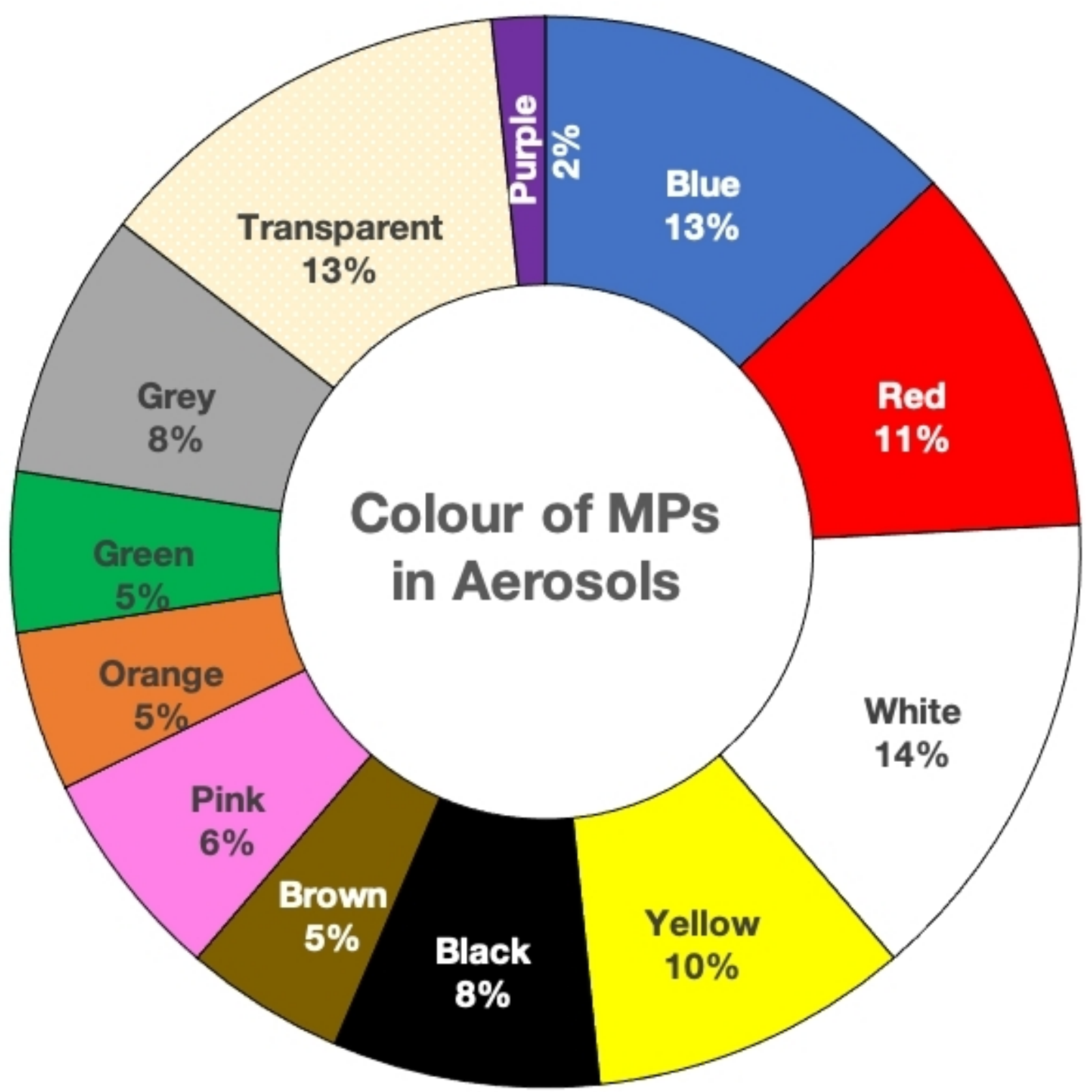

Figure 10. Color of microplastics (MPs) found in aerosol samples.

passive sampling by atmospheric deposition, taking swipes over a surface, and relating them to inhalation is no better than a first-order approximation.

Some other aspects of atmospheric MP research that need some discussion and consensus are the following: should the active and passive sampling techniques be used in tandem to answer questions on health risk and seasonal MP loading and accumulation rates over a long period? The emphasis on polymeric characterization is significant in current MP research, and it is certainly important to know what are the dominant polymers for source apportionment, but is there much value of this effort for environmental or human health risk assessment? A simpler hot needle technique can provide equally useful information. 
It has been observed in MP research that significant issues of degradation, losses, and cross-contamination are introduced due to sample processing, be it the use of impure salts for making solutions, discoloration due to $\mathrm{H}_{2} \mathrm{O}_{2}$, or degradation due to use of acids, the use of inappropriate filters to separate MPs from associated matrices, or heating of sample while processing and cross-contamination during microscopic examination. From our experience and a comparative study (unpublished), we found that the use of an active sampler with cascade impactor and without any filter media provided a cleaner, size-fractionated aerosol sample that can be directly subjected to microscopic examination under stereomicroscope and UV florescence microscope after staining with Nile red. The hot needle technique was found to be very effective to differentiate MPs from natural fibers.

This review also highlights the fact that most researchers use a multi-tier approach for MP identification, with the first step using microscopy, followed by polymeric characterization. Another pertinent issue is the variable set of information provided by different researchers; there is no standardization of nomenclature, with some researchers only indicating the use of FTIR without specifying ATR or micro. The nomenclature for shape is also quite variable. Some researchers have only indicated particles, others have been specific about fibers and fragments, some have used the term "spherules", and others have used "granules", making it a difficult task to standardize and compare them. Many studies have deployed passive samplers, but with no ancillary data or discussion on wind directions, velocities, dust loadings, etc. that prevailed during sample collection. With all this missing information, readers cannot make any realistic inferences on likely health implications, which is the core of this research.

Several researchers have reported color of MPs, but will this knowledge have any implication for risk? Can color itself in the absence of other parameters be of any use? The measurement of length and diameter is done under a microscope and is often a tedious task, so would the use of a size-fractionated cascade impactor be a better approach for size segregation while sampling?

The most important aspect of atmospheric MP research is the human health implications. It is well established that $\mathrm{PM}_{10}$ and $\mathrm{PM}_{2.5}$ are extremely important particle sizes for pulmonary risk assessments. Most studies have not addressed these size fractions ${ }^{[114]}$. In addition, the use of ATR-FTIR and $\mu$-FTIR cannot help in polymeric identification of $<10 \mu \mathrm{m}$ particles, so will it help in human health risk assessment due to inhalation where $\mathrm{PM}_{2.5}$ and finer particle sizes are more important to assess the respirable fraction? On the other hand, the $\mu$-RS can provide polymer identification of MP up to $1 \mu \mathrm{m}$ that can be more useful, but does polymer type make a difference, or is it the size that matters? Should there be an emphasis on the use of aerosol size fractions or the total number of MPs per cubic meter or liter to generate meaningful information for human health risk?

Does the information from TGA, HPLC-MS-MS, and pyro GC-MS on polymer mass in milligrams per cubic meter have any use without knowing to which size fraction it belongs? Are they inhalable or respirable? Is it reasonable to report number of MP per unit mass of size-fractionated aerosol ( $\mathrm{MP} \mathrm{mg}^{-1}$ of the aerosol fraction)? This will be a technological challenge due to their infinitesimal mass in even large sample volumes.

The review overwhelmingly highlights the need to harmonize the methodology for studying MPs in aerosol. There is an urgent need to discuss the importance for using size fractionation, polymeric characterization, sample volumes, and reporting units keeping in mind what is actually useful for the scientific question one is addressing. 


\section{DECLARATIONS}

\section{Acknowledgments}

Authors acknowledge support from Kuwait Institute for Scientific Research for this study.

\section{Authors' contributions}

Conceptualization: Habibi N, Uddin S, Fowler SW

Methodology: Habibi N, Uddin S

Software: Habibi N

Formal analysis: Habibi N, Uddin S

Investigation: Uddin S, Behbehani M, Habibi N

Data curation: Behbehani M

Writing - original draft preparation: Habibi N, Uddin S, Behbehani M

Writing - review and editing: Uddin S, Habibi N, Fowler SW

Visualization: Habibi N

All authors have read and agreed to the published version of the manuscript.

\section{Availability of data and materials}

The data presented in this review are available as a supplementary file.

\section{Financial support and sponsorship}

None.

\section{Conflicts of interest}

All authors declared that there are no conflicts of interest.

\section{Ethical approval and consent to participate}

Not applicable.

\section{Consent for publication}

Not applicable.

\section{Copyright}

(c) The Author(s) 2022.

\section{REFERENCES}

1. Anon. More than 8.3 billion tons of plastics made: most has now been discarded. Available from: https://scholar.google.com/scholar?cluster=5262591584792555541\&hl=zh-CN\&as_sdt=2005\&sciodt=0,5 [Last accessed on 20 Jan 2022].

2. Geyer R, Jambeck JR, Law KL. Production, use, and fate of all plastics ever made. Sci Adv 2017;3:e1700782. DOI PubMed PMC

3. Jambeck JR, Geyer R, Wilcox C, et al. Marine pollution. Plastic waste inputs from land into the ocean. Science 2015;347:768-71. DOI PubMed

4. Barboza LGA, Cózar A, Gimenez BCG, et al. Macroplastics pollution in the marine environment. World seas: an environmental evaluation. London: Academic Press; 2019. p. 305-28. DOI

5. Tekman MB, Gutow L, Macario A, Haas A, Walter A, Bergmann M. Alfred-wegener-institut helmholtz-zentrum für Polar- und meeresforschung. Available from: https://litterbase.awi.de/litter_detail 2019 [Last accessed on 20 Jan 2022].

6. Song YK, Hong SH, Jang M, Han GM, Jung SW, Shim WJ. Combined effects of UV exposure duration and mechanical abrasion on microplastic fragmentation by polymer type. Environ Sci Technol 2017;51:4368-76. DOI PubMed

7. Wright SL, Ulke J, Font A, Chan KLA, Kelly FJ. Atmospheric microplastic deposition in an urban environment and an evaluation of transport. Environ Int 2020;136:105411. DOI PubMed PMC

8. Eriksen M, Lebreton LC, Carson HS, et al. Plastic pollution in the world's oceans: more than 5 trillion plastic pieces weighing over 250,000 tons afloat at sea. PLoS One 2014;9:e111913. DOI PubMed PMC

9. Uddin S, Fowler SW, Behbehani M. An assessment of microplastic inputs into the aquatic environment from wastewater streams. Mar Pollut Bull 2020;160:111538. DOI PubMed 
10. Enyoh CE, Verla AW, Verla EN, Ibe FC, Amaobi CE. Airborne microplastics: a review study on method for analysis, occurrence, movement and risks. Environ Monit Assess 2019;191:668. DOI PubMed

11. Gasperi J, Wright SL, Dris R, et al. Microplastics in air: are we breathing it in? Current Opinion in Environmental Science \& Health 2018;1:1-5. DOI

12. Vianello A, Jensen RL, Liu L, Vollertsen J. Simulating human exposure to indoor airborne microplastics using a Breathing Thermal Manikin. Sci Rep 2019;9:8670. DOI PubMed PMC

13. Prata JC. Airborne microplastics: consequences to human health? Environ Pollut 2018;234:115-26. DOI PubMed

14. Uddin S, Gevao B, Talebi L, et al. Estimation of PM2. 5 concentrations using satellite data, with spatio-temporal variations of chemicals associated with PM. Final Report EM057K. Kuwait Institute for Scientific Research 2013:1-74.

15. Allen S, Allen D, Phoenix VR, et al. Atmospheric transport and deposition of microplastics in a remote mountain catchment. Nat Geosci 2019;12:339-44. DOI

16. Abbasi S, Keshavarzi B, Moore F, et al. Distribution and potential health impacts of microplastics and microrubbers in air and street dusts from Asaluyeh County, Iran. Environ Pollut 2019;244:153-64. DOI PubMed

17. Akanyange SN, Lyu X, Zhao X, et al. Does microplastic really represent a threat? Sci Total Environ 2021;777:146020. DOI PubMed

18. Dris R, Gasperi J, Rocher V, Saad M, Renault N, Tassin B. Microplastic contamination in an urban area: a case study in Greater Paris. Environ Chem 2015;12:592. DOI

19. Dris R, Gasperi J, Saad M, Mirande C, Tassin B. Synthetic fibers in atmospheric fallout: a source of microplastics in the environment? Mar Pollut Bull 2016;104:290-3. DOI PubMed

20. Dris R, Gasperi J, Mirande C, et al. A first overview of textile fibers, including microplastics, in indoor and outdoor environments. Environ Pollut 2017;221:453-8. DOI PubMed

21. Dris R, Gasperi J, Tassin B. Sources and fate of microplastics in urban areas: a focus on paris megacity. In: Wagner M, Lambert S, editors. Freshwater microplastics. Cham: Springer International Publishing; 2018. p. 69-83. DOI

22. Liao Z, Ji X, Ma Y, et al. Airborne microplastics in indoor and outdoor environments of a coastal city in Eastern China. J Hazard Mater 2021;417:126007. DOI PubMed

23. Prata JC, Castro JL, da Costa JP, Duarte AC, Rocha-Santos T, Cerqueira M. The importance of contamination control in airborne fibers and microplastic sampling: Experiences from indoor and outdoor air sampling in Aveiro, Portugal. Mar Pollut Bull 2020;159:111522. DOI PubMed

24. Soltani NS, Taylor MP, Wilson SP. Quantification and exposure assessment of microplastics in Australian indoor house dust. Environ Pollut 2021;283:117064. DOI PubMed

25. Wright SL, Levermore JM, Kelly FJ. Raman spectral imaging for the detection of inhalable microplastics in ambient particulate matter samples. Environ Sci Technol 2019;53:8947-56. DOI PubMed

26. Wright SL, Gouin T, Koelmans AA, Scheuermann L. Development of screening criteria for microplastic particles in air and atmospheric deposition: critical review and applicability towards assessing human exposure. Micropl \&Nanopl 2021;1:6. DOI

27. Napper IE, Thompson RC. Release of synthetic microplastic plastic fibres from domestic washing machines: effects of fabric type and washing conditions. Mar Pollut Bull 2016;112:39-45. DOI PubMed

28. Henry B, Laitala K, Klepp IG. Microfibres from apparel and home textiles: prospects for including microplastics in environmental sustainability assessment. Sci Total Environ 2019;652:483-94. DOI PubMed

29. Falco F, Di Pace E, Cocca M, Avella M. The contribution of washing processes of synthetic clothes to microplastic pollution. Sci Rep 2019;9:6633. DOI PubMed PMC

30. Browne MA, Crump P, Niven SJ, et al. Accumulation of microplastic on shorelines woldwide: sources and sinks. Environ Sci Technol 2011;45:9175-9. DOI PubMed

31. Wu D, Li Q, Shang X, et al. Commodity plastic burning as a source of inhaled toxic aerosols. J Hazard Mater 2021;416:125820. DOI PubMed

32. Velis CA, Cook E. Mismanagement of plastic waste through open burning with emphasis on the global south: a systematic review of risks to occupational and public health. Environ Sci Technol 2021;55:7186-207. DOI PubMed

33. Wright SL, Kelly FJ. Plastic and human health: a micro issue? Environ Sci Technol 2017;51:6634-47. DOI PubMed

34. Pauly JL, Stegmeier SJ, Allaart HA, et al. Inhaled cellulosic and plastic fibers found in human lung tissue. Cancer Epidemiol Biomarkers Prev 1998;7:419-28. PubMed

35. Law BD, Bunn WB, Hesterberg TW. Solubility of polymeric organic fibers and manmade vitreous fibers in gambles solution. Inhal Toxicol 2008;2:321-39. DOI

36. Boag AH, Colby TV, Fraire AE, et al. The pathology of interstitial lung disease in nylon flock workers. Am J Surg Pathol 1999;23:1539-45. DOI PubMed

37. Eschenbacher WL, Kreiss K, Lougheed MD, Pransky GS, Day B, Castellan RM. Nylon flock-associated interstitial lung disease. Am J Respir Crit Care Med 1999;159:2003-8. DOI PubMed

38. Kremer AM, Pal TM, Boleij JS, Schouten JP, Rijcken B. Airway hyper-responsiveness and the prevalence of work-related symptoms in workers exposed to irritants. Am J Ind Med 1994;26:655-69. DOI PubMed

39. Brennecke D, Ferreira EC, Costa TM, Appel D, da Gama BA, Lenz M. Ingested microplastics $(>100 \mu \mathrm{m})$ are translocated to organs of the tropical fiddler crab Uca rapax. Mar Pollut Bull 2015;96:491-5. DOI PubMed

40. Carbery M, O'Connor W, Palanisami T. Trophic transfer of microplastics and mixed contaminants in the marine food web and implications for human health. Environ Int 2018;115:400-9. DOI PubMed 
41. Amato-Lourenço LF, Dos Santos Galvão L, de Weger LA, Hiemstra PS, Vijver MG, Mauad T. An emerging class of air pollutants: potential effects of microplastics to respiratory human health? Sci Total Environ 2020;749:141676. DOI PubMed PMC

42. Alimba CG, Faggio C. Microplastics in the marine environment: current trends in environmental pollution and mechanisms of toxicological profile. Environ Toxicol Pharmacol 2019;68:61-74. DOI PubMed

43. Andrady AL. Microplastics in the marine environment. Mar Pollut Bull 2011;62:1596-605. DOI PubMed

44. Andrady AL. The plastic in microplastics: a review. Mar Pollut Bull 2017;119:12-22. DOI PubMed

45. Auta HS, Emenike CU, Fauziah SH. Distribution and importance of microplastics in the marine environment: a review of the sources, fate, effects, and potential solutions. Environ Int 2017;102:165-76. DOI PubMed

46. Brennecke D, Duarte B, Paiva F, Caçador I, Canning-clode J. Microplastics as vector for heavy metal contamination from the marine environment. Estuar Coast Shelf Sci 2016;178:189-95. DOI

47. Sá LC, Oliveira M, Ribeiro F, Rocha TL, Futter MN. Studies of the effects of microplastics on aquatic organisms: what do we know and where should we focus our efforts in the future? Sci Total Environ 2018;645:1029-39. DOI PubMed

48. Esmaili Z, Naji A. Comparison of the frequency, type and shape of microplastics in the low and high tidal of the coastline of Bandar Abbas. J Oceanogr 2018;8:53-61. DOI

49. Fahrenfeld N, Arbuckle-keil G, Naderi Beni N, Bartelt-hunt SL. Source tracking microplastics in the freshwater environment. Trends Analyt Chem 2019;112:248-54. DOI

50. Hidalgo-Ruz V, Gutow L, Thompson RC, Thiel M. Microplastics in the marine environment: a review of the methods used for identification and quantification. Environ Sci Technol 2012;46:3060-75. DOI PubMed

51. Lusher A. Microplastics in the marine environment: distribution, interactions and effects. In: Bergmann M, Gutow L, Klages M, editors. Marine anthropogenic litter. Cham: Springer International Publishing; 2015. p. 245-307. DOI

52. Maes T, Jessop R, Wellner N, Haupt K, Mayes AG. A rapid-screening approach to detect and quantify microplastics based on fluorescent tagging with Nile Red. Sci Rep 2017;7:44501. DOI PubMed PMC

53. Rodrigues JP, Duarte AC, Santos-echeandía J, Rocha-santos T. Significance of interactions between microplastics and POPs in the marine environment: a critical overview. Trends Analyt Chem 2019;111:252-60. DOI

54. Schymanski D, Goldbeck C, Humpf HU, Fürst P. Analysis of microplastics in water by micro-Raman spectroscopy: Release of plastic particles from different packaging into mineral water. Water Res 2018;129:154-62. DOI PubMed

55. Allen S, Allen D, Phoenix VR, et al. Atmospheric transport and deposition of microplastics in a remote mountain catchment. Nature Geoscience 2019;12:339-44. DOI

56. Vroom RJE, Koelmans AA, Besseling E, Halsband C. Aging of microplastics promotes their ingestion by marine zooplankton. Environ Pollut 2017;231:987-96. DOI PubMed

57. Wagner M, Scherer C, Alvarez-Muñoz D, et al. Microplastics in freshwater ecosystems: what we know and what we need to know. Environ Sci Eur 2014;26:12. DOI PubMed PMC

58. Wan J, Chu W, Kok Y, Lee C. Distribution of microplastics and nanoplastics in aquatic ecosystems and their impacts on aquatic organisms, with emphasis on microalgae. Rev Environ Contam Toxicol 2018. DOI PubMed

59. Zhang S, Wang J, Liu X, et al. Microplastics in the environment: a review of analytical methods, distribution, and biological effects. Trends Analyt Chem 2019;111:62-72. DOI

60. Endo S, Yuyama M, Takada H. Desorption kinetics of hydrophobic organic contaminants from marine plastic pellets. Mar Pollut Bull 2013;74:125-31. DOI PubMed

61. Franck U, Leitte AM, Suppan P. Multifactorial airborne exposures and respiratory hospital admissions--the example of Santiago de Chile. Sci Total Environ 2015;502:114-21. DOI PubMed

62. Smith M, Love DC, Rochman CM, Neff RA. Microplastics in seafood and the implications for human health. Curr Environ Health Rep 2018;5:375-86. DOI PubMed PMC

63. Berkner S, Streck G, Herrmann R. Development and validation of a method for determination of trace levels of alkylphenols and bisphenol A in atmospheric samples. Chemosphere 2004;54:575-84. DOI PubMed

64. Graziani NS, Carreras H, Wannaz E. Atmospheric levels of BPA associated with particulate matter in an urban environment. Heliyon 2019;5:e01419. DOI PubMed PMC

65. Amato-Lourenço LF, Carvalho-Oliveira R, Júnior GR, Dos Santos Galvão L, Ando RA, Mauad T. Presence of airborne microplastics in human lung tissue. J Hazard Mater 2021;416:126124. DOI PubMed

66. Wang Y, Ding D, Shu M, et al. Characteristics of indoor and outdoor fine phthalates during different seasons and haze periods in Beijing. Aerosol Air Qual Res 2019;19:364-74. DOI

67. Schins RP. Mechanisms of genotoxicity of particles and fibers. Inhal Toxicol 2002;14:57-78. DOI PubMed

68. Uddin S. Use of satellite images to map spatio-temporal variability of PM2. 5 in air. Athens $J$ Sci 2016;3:183-98. DOI

69. Dommergue A, Amato P, Tignat-Perrier R, et al. Methods to investigate the global atmospheric microbiome. Front Microbiol 2019;10:243. DOI PubMed PMC

70. William T. Compendium method IO-2.1, sampling of ambient air for total suspended particulate matter (SPM) and PM10 using high volume (HV) sampler. Available from: https://19january2017snapshot.epa.gov/sites/production/files/2015-07/documents/epa-io2.1.pdf [Last accessed on 20 Jan 2022].

71. Uddin S, Fowler S W, Habibi N, Sajid S, Dupont S, Behbehani M. A preliminary assessment of size fractionated microplastics in indoor aerosol - Kuwait's baseline. Toxics 2022:toxics-1263126.

72. Zhou Q, Tian C, Luo Y. Various forms and deposition fluxes of microplastics identified in the coastal urban atmosphere. Chin Sci Bull 2017;62:3902-9. DOI 
73. Cai L, Wang J, Peng J, et al. Characteristic of microplastics in the atmospheric fallout from Dongguan city, China: preliminary research and first evidence. Environ Sci Pollut Res Int 2017;24:24928-35. DOI PubMed

74. Klein M, Fischer EK. Microplastic abundance in atmospheric deposition within the Metropolitan area of Hamburg, Germany. Sci Total Environ 2019;685:96-103. DOI PubMed

75. Stanton T, Johnson M, Nathanail P, MacNaughtan W, Gomes RL. Freshwater and airborne textile fibre populations are dominated by 'natural', not microplastic, fibres. Sci Total Environ 2019;666:377-89. DOI

76. Abbasi S, Keshavarzi B, Moore F, Delshab H, Soltani N, Sorooshian A. Investigation of microrubbers, microplastics and heavy metals in street dust: a study in Bushehr city, Iran. Environ Earth Sci 2017:76. DOI

77. Dehghani S, Moore F, Akhbarizadeh R. Microplastic pollution in deposited urban dust, Tehran metropolis, Iran. Environ Sci Pollut Res Int 2017;24:20360-71. DOI PubMed

78. Liu C, Li J, Zhang Y, et al. Widespread distribution of PET and PC microplastics in dust in urban China and their estimated human exposure. Environ Int 2019;128:116-24. DOI PubMed

79. Kaya A, Yurtsever M, Çiftçi Bayraktar S. Ubiquitous exposure to microfiber pollution in the air. Eur Phys J Plus 2018:133. DOI

80. Liu K, Wang X, Fang T, Xu P, Zhu L, Li D. Source and potential risk assessment of suspended atmospheric microplastics in Shanghai. Sci Total Environ 2019;675:462-71. DOI PubMed

81. Liu K, Wu T, Wang X, et al. Consistent transport of terrestrial microplastics to the ocean through atmosphere. Environ Sci Technol 2019;53:10612-9. DOI PubMed

82. Syafei AD, Nurasrin NR, Assomadi AF, Boedisantoso R. Microplastic pollution in the ambient air of Surabaya, Indonesia. Curr World Environ 2019;14:290-8. DOI

83. Zhang J, Wang L, Kannan K. Microplastics in house dust from 12 countries and associated human exposure. Environ Int 2020;134:105314. DOI PubMed

84. Jenner LC, Sadofsky LR, Danopoulos E, Rotchell JM. Household indoor microplastics within the Humber region (United Kingdom): quantification and chemical characterisation of particles present. Atmospheric Environment 2021;259:118512. DOI

85. Uddin S, Fowler SW, Uddin MF, Behbehani M, Naji A. A review of microplastic distribution in sediment profiles. Mar Pollut Bull 2021;163:111973. DOI PubMed

86. Löder MGJ, Imhof HK, Ladehoff M, et al. Enzymatic purification of microplastics in environmental samples. Environ Sci Technol 2017;51:14283-92. DOI PubMed

87. Renner G, Schmidt TC, Schram J. Analytical methodologies for monitoring micro(nano)plastics: which are fit for purpose? Current Opinion in Environmental Science \& Health 2018;1:55-61. DOI

88. Uddin S, Fowler SW, Saeed T. Microplastic particles in the Persian/Arabian Gulf - a review on sampling and identification. Mar Pollut Bull 2020;154:111100. DOI PubMed

89. Al-Salem SM, Uddin S, Lyons B. Evidence of microplastics (MP) in gut content of major consumed marine fish species in the State of Kuwait (of the Arabian/Persian Gulf). Mar Pollut Bull 2020;154:111052. DOI PubMed

90. Bessa F, Frias J, Kögel T, et al. Harmonized protocol for monitoring microplastics in biota; JPI-Oceans BASEMAN Project, 2019.

91. Gago J, Galgani F, Maes T, Thompson RC. Microplastics in Seawater: Recommendations from the Marine Strategy Framework Directive Implementation Process. Front Mar Sci 2016:3. DOI

92. Uddin S, Fowler SW, Saeed T, Naji A, Al-Jandal N. Standardized protocols for microplastics determinations in environmental samples from the Gulf and marginal seas. Mar Pollut Bull 2020;158:111374. DOI PubMed

93. Cauwenberghe L, Devriese L, Galgani F, Robbens J, Janssen CR. Microplastics in sediments: a review of techniques, occurrence and effects. Mar Environ Res 2015;111:5-17. DOI PubMed

94. Akhbarizadeh R, Dobaradaran S, Nabipour I, et al. Abandoned covid-19 personal protective equipment along the Bushehr shores, the Persian Gulf: An emerging source of secondary microplastics in coastlines. Mar Pollut Bull 2021;168:112386. DOI PubMed PMC

95. Marina-montes C, Pérez-arribas LV, Anzano J, Cáceres JO. Local and remote sources of airborne suspended particulate matter in the antarctic region. Atmosphere 2020;11:373. DOI

96. Roblin B, Ryan M, Vreugdenhil A, Aherne J. Ambient atmospheric deposition of anthropogenic microfibers and microplastics on the western periphery of europe (Ireland). Environ Sci Technol 2020;54:11100-8. DOI PubMed

97. Trainic M, Flores JM, Pinkas I, et al. Airborne microplastic particles detected in the remote marine atmosphere. Commun Earth Environ 2020;1:64. DOI

98. Yao Y, Glamoclija M, Murphy A, Gao Y. Characterization of microplastics in indoor and ambient air in northern New Jersey. Environ Res 2021:112142. DOI PubMed

99. Levermore JM, Smith TEL, Kelly FJ, Wright SL. Detection of microplastics in ambient particulate matter using raman spectral imaging and chemometric analysis. Anal Chem 2020;92:8732-40. DOI PubMed

100. Peñalver R, Arroyo-Manzanares N, López-García I, Hernández-Córdoba M. An overview of microplastics characterization by thermal analysis. Chemosphere 2020;242:125170. DOI PubMed

101. Bergmann M, Mützel S, Primpke S, Tekman MB, Trachsel J, Gerdts G. White and wonderful? Sci Adv 2019;5:eaax1157. DOI PubMed PMC

102. Barnes DK, Galgani F, Thompson RC, Barlaz M. Accumulation and fragmentation of plastic debris in global environments. Philos Trans R Soc Lond B Biol Sci 2009;364:1985-98. DOI PubMed PMC

103. Cole M, Lindeque P, Halsband C, Galloway TS. Microplastics as contaminants in the marine environment: a review. Mar Pollut Bull 2011;62:2588-97. DOI PubMed

104. Hartmann NB, Hüffer T, Thompson RC, et al. Are we speaking the same language? Environ Sci Technol 2019;53:1039-47. DOI 
PubMed

105. Liu K, Wang X, Wei N, Song Z, Li D. Accurate quantification and transport estimation of suspended atmospheric microplastics in megacities: Implications for human health. Environ Int 2019;132:105127. DOI PubMed

106. Gaston E, Woo M, Steele C, Sukumaran S, Anderson S. Microplastics differ between indoor and outdoor air masses: insights from multiple microscopy methodologies. Appl Spectrosc 2020;74:1079-98. DOI PubMed

107. Scopetani C, Chelazzi D, Cincinelli A, Esterhuizen-Londt M. Assessment of microplastic pollution: occurrence and characterisation in Vesijärvi lake and Pikku Vesijärvi pond, Finland. Environ Monit Assess 2019;191:652. DOI PubMed PMC

108. Narmadha VV, Jose J, Patil S, et al. Assessment of microplastics in roadside suspended dust from urban and rural environment of Nagpur, India. Int J Environ Res 2020;14:629-40. DOI

109. Truong TN, Strady E, Kieu-Le TC, Tran QV, Le TM, Thuong QT. Microplastic in atmospheric fallouts of a developing Southeast Asian megacity under tropical climate. Chemosphere 2021;272:129874. DOI PubMed

110. Szewc K, Graca B, Dołęga A. Atmospheric deposition of microplastics in the coastal zone: characteristics and relationship with meteorological factors. Sci Total Environ 2021;761:143272. DOI PubMed

111. Wang F, Lai Z, Peng G, et al. Microplastic abundance and distribution in a Central Asian desert. Sci Total Environ 2021;800:149529. DOI PubMed

112. Ding Y, Zou X, Wang C, et al. The abundance and characteristics of atmospheric microplastic deposition in the northwestern South China Sea in the fall. Atmospheric Environment 2021;253:118389. DOI

113. Prata JC. Microplastics in wastewater: state of the knowledge on sources, fate and solutions. Mar Pollut Bull 2018;129:262-5. DOI PubMed

114. Uddin S, Fowler SW, Habibi N, Behbehani M. Micro-nanoplastics in aquatic environments: effects on animal health and human food safety. Animals 2022:1464987. 